\title{
An Easy and Reliable Way to Prevent Electrocardiographic Deteriorations of Patients Undergoing Off-Pump Coronary Artery Bypass Surgery: Preoperative Anxiolytic Treatment
}

\author{
Abdullah Demirhan' ${ }^{1}$, MD; Yusuf Velioglu², MD; Hamit Yoldas ${ }^{1}$, MD; Ibrahim Karagoz ${ }^{1}$, MD; Mehmet Cosgun ${ }^{3}$, MD; \\ Duygu Caliskan ${ }^{1}$, MD; Isa Yildiz ${ }^{1}$, MD; Murat Bilgi ${ }^{1}$, MD; Kemalettin Erdem² ${ }^{2}$ MD
}

DOI: $10.21470 / 1678-9741-2018-0282$

\section{Abstract}

Objective: To investigate the effects of preoperative anxiety relieving on electrophysiological changes in patients undergoing off-pump coronary artery bypass surgery.

Methods: A total of 61 patients at ASA III risk group in the age range of 18-65 years were enrolled in the present study. Patients were randomly divided into two groups. Group $S$ (Sedation group) was administered $0.04 \mathrm{mg} / \mathrm{kg}$ lorazepam per os (PO) twice before the operation. Group C (control group) was not administered with any anxiolytic premedication. State Trait Anxiety Inventory (STAI-I) and Beck Anxiety Inventory (BAI) were used to evaluate the level of anxiety. Electrocardiography (ECG), pulse oximeter and standard monitoring were performed for each patient. QT and $P$ dispersions in each derivation of all ECGs were calculated.

Results: Preoperative STAI-I scores were significantly lower in sedation group compared to the controls. Mean values of
QT dispersion measured before induction, at the 1st minute of induction, 30th second of intubation and 4th minute of intubation in sedation group were significantly reduced compared to controls $(P=0.024 ; P=0.027 ; P=0.001 ; P=0.033$, respectively). The mean values of $P$ dispersion measured before induction, at the 3rd minute of induction, 30th second of intubation and 4th minute of intubation in sedation group were significantly reduced compared to controls ( $P=0.001 ; P=0.020 ; P=0.023 ; P=0.005$, respectively).

Conclusion: Elevated anxiety levels in patients undergoing coronary bypass surgery have a negative effect through prolonged QT and P-wave dispersion times. Anxiolytic treatment before surgery may be useful to prevent ventricular and atrial arrhythmias and associated complications through decreasing the QT and P-wave dispersion duration.

Keywords: Anxiety. P-Wave Dispersion. QT Dispersion. OffPump Coronary Artery Bypass Surgery.

$$
\text { Abbreviations, acronyms \& symbols }
$$

$\begin{array}{ll}\text { ASA } & =\text { American Society of Anesthesiologists } \\ \text { BAI } & =\text { Beck Anxiety Inventory } \\ \text { BMI } & =\text { Body mass index } \\ \text { DBP } & =\text { Diastolic blood pressure } \\ \text { ECG } & =\text { Electrocardiography } \\ \text { HR } & =\text { Heart rate } \\ \text { HT } & =\text { Heart transplantation } \\ \text { MAP } & =\text { Mean arterial pressure } \\ \text { QTC } & =\text { Corrected QT interval }\end{array}$

Pd $\quad=$ P-wave dispersion

PO $\quad=$ Peros

QTC $\quad=$ Corrected QT

QTd = QT dispersion

SBP = Systolic blood pressure

SPSS = Statistical Package for Social Science

STAI-I = State Trait Anxiety Inventory

$\mathrm{TI} \quad=$ Tracheal intubation
'Department of Anesthesiology and Reanimation, Abant Izzet Baysal University Medical School, Bolu, Turkey.

${ }^{2}$ Department of Cardiovascular Surgery, Abant Izzet Baysal University Medical School, Bolu, Turkey.

${ }^{3}$ Department of Cardiology, Abant Izzet Baysal University Medical School, Bolu, Turkey.

This study was carried out at the Department of Anesthesiology and Reanimation, Abant Izzet Baysal University Medical School, Bolu, Turkey.
Correspondence Address: Abdullah Demirhan

(iD) https://orcid.org/0000-0002-2311-6431 Department of Anesthesiology and Reanimation

Abant Izzet Baysal University Medical School, Golkoy, Bolu, Turkey Zip code: 14280

E-mail:dr_demirhan1@hotmail.com

Article received on September $12^{\text {th }}, 2018$. Article accepted on November 4th, 2018. 


\section{INTRODUCTION}

Major cardiac surgery causes fear, stress and anxiety on many patients $^{[1-5]}$. Due to concern, fear and due to some unknown reasons, it is stated that patients may experience high levels of anxiety prior to cardiac surgery ${ }^{[6]}$. It has been previously shown that one or two days before cardiac surgery the anxiety levels of patients rises up to $20-50 \%[2,3]$.

Anxiety, depression and negative thoughts may also cause pathological changes ${ }^{[7]}$. It has been found that increased anxiety leads to sympathetic hyperactivity through elevated levels of serotonin, dopamine, plasma norepinephrine and metabolites in patients ${ }^{[8,9]}$. This, in return, decreases the ventricular fibrillation threshold via prolonged and increased dispersion of repolarization ${ }^{[10]}$. It has been shown in the literature that increased anxiety and stress levels may increase the likelihood of cardiac arrhythmia through prolonged QT dispersion (QTd) ${ }^{[11,12]}$.

It is known that coronary bypass surgery causes more catecholamine release during laryngoscopy and tracheal intubation ( $\mathrm{Tl}$ ) compared to other operations, resulting in a sudden increase in blood pressure and heart rate $(H R)^{[13,14]}$. Previous studies have also shown that increased plasma levels of catecholamine increase P-wave dispersion $(\mathrm{Pd})$ on electrocardiography, prolong corrected QT (QTC) distance, and QT dispersion. Moreover, Pd changes have been associated with atrial arrhythmias, however, changes in QTC and QTd were associated with ventricular arrhythmia and sudden death ${ }^{[15-17]}$.

Electrocardiography (ECG) is a reliable indicator that is frequently used to detect pathological electrical activity. The QT interval is an indicative of ventricular repolarization, and its extension is considered a risk factor for arrhythmias ${ }^{[18]}$. QT dispersion is defined as the difference between the longest QT and the shortest QT of the 12-lead ECG reflecting the different regions of ventricular repolarization. Laryngoscopy and TI in anesthesia induction increases HR and mean arterial pressure (MAP) values, as well as changes the electrophysiological properties of the heart ${ }^{[19-23]}$. In the literature, inhalers have been shown to extend QT interval following anesthetic agents and T[ ${ }^{[24,25]}$.

In this study, we investigated the effects of relieving preoperative anxiety on electrophysiological changes in patients who will undergo off-pump coronary artery bypass surgery. In these patients, high levels of stress are induced during preinduction, as well as laryngoscopy and tracheal intubation.

\section{METHODS}

The present randomized controlled study was performed after approval of the Abant Izzet Baysal University Ethics Committee for Clinical Researches by 2017/05. All patients provided their written and oral consent to participate in the study during preoperative examination. All patients underwent off-pump coronary artery bypass grafting surgery under general anesthesia, performed in Abant Izzet Baysal University at the Training Research Hospital. A total of 61 patients in ASA III risk group in the age range of 18-65 years were enrolled in the present study. Sixty-one patients, who agreed to participate in the study, were randomly divided into two groups. The group administered with anxiolytic-sedative drug was called Group S
(Sedation group), and the group that was not administered any anxiolytic-sedative drug was called Group C (Control group). Group S was administered $0.04 \mathrm{mg} / \mathrm{kg}$ lorazepam per os (PO) twice; once the night before the operation, then 2 hours before the operation. Group C was not administered with any anxiolytic premedication.

Evaluations were performed and recorded using both the State Trait Anxiety Inventory-TX1 (STAI-I) form, consisting of 20 parameters, and the Beck Anxiety Inventory (BAI), consisting of 21 parameters for the state anxiety measurement of the patients. STAI-I is used to show the individual differences in anxiety levels, which is intensified in response to potentially threatening events $^{[26]}$. In this questionnaire, a total score of 20 to 80 was given to each participant using a 4-point Likert scale. In this test, higher scores are indicative of elevated anxiety levels ${ }^{[26-28]}$. BAI was scored from 0 to 3 using a 4-point Likert scale. This test is used to focus on somatic symptoms of anxiety ${ }^{[29]}$.

On the day of operation, the STAI-I and BAI evaluations were performed by a practitioner who did not know the patient's groups. In the operating room, 16-18 G intravenous catheters were inserted into separate arms and $0.05 \mathrm{mg} / \mathrm{kg}$ morphine was administered intravenously to provide sedation. For all patients, ECG for heart rate $(\mathrm{HR})$, pulse oximetry $\left(\mathrm{SpO}_{2}\right)$ for peripheral oxygen saturation and standard monitoring were performed. Moreover, to monitor the arterial blood pressure, Allen test was performed from a normal arm under topical anesthesia using a 20G catheter. The systolic blood pressure (SBP), diastolic blood pressure (DBP) and MAP parameters were also recorded. Furthermore, during preanesthetic induction, patients were connected with standard 12-lead ECG (Nihon Kohden, Model EKG-1350K, Japan) to confirm sinus rhythm and pre-induction ECG recording was obtained. ECG recordings were performed at a speed of $25 \mathrm{~mm} / \mathrm{sec}$.

Anesthesia induction was started using 1-2 mg/kg propofol and $2 \mathrm{mcg} / \mathrm{kg}$ fentanyl. After loss of consciousness, muscle relaxation was achieved with $0.6 \mathrm{mg} / \mathrm{kg}$ rocuronium. This is followed by face mask ventilation for 3 minutes. Then, patients were intubated using a tube of similar size (size 8). Following the 12-lead ECG induction of the patients, after induction at the $1^{\text {st }}$ and $3^{\text {rd }}$ minutes, as well as after intubation, at the $30^{\text {th }}$ second in the $2^{\text {nd }}$ and $4^{\text {th }}$ minutes, records were taken. Then, the anesthesia was continued with air and 1-2\% sevoflurane in 50\% oxygen. At the same time, central venous catheter was inserted, and hemodynamic parameters, including HR and MAP, were measured and recorded before induction, after induction at the $1^{\text {st }}$ and $3^{\text {rd }}$ minutes, as well as after intubation and at the $30^{\text {th }}$ second in the $2^{\text {nd }}$ and $4^{\text {th }}$ minutes. QT and P dispersion in each derivation of all ECGs was calculated by a cardiologist and anesthesiologist. The QT dispersion was calculated as the difference between the maximum and minimum QT values (QTd = maximum QT - minimum QT). Likewise, P dispersion was calculated as the difference between the maximum and minimum P-values.

\section{Statistical Analysis}

The Statistical Package for Social Science (SPSS 23.0) program was used to perform statistical analysis. The descriptive variables age, body mass index (BMI), QT dispersion, P dispersion, and MAP 
were calculated as mean \pm standard deviation. The KolmogorovSmirnov test was used to determine whether variables were normally distributed. Independent-Samples T-test was used to analyze the normally distributed variables between the groups. Analysis of variance for repeated measures was used to compare QT dispersion, P dispersion and MAP at different intubation time periods. When a significant overall effect was detected, Tukey's post-hoc test was conducted for comparison of the mean values for the two variables. The chi-squared and Fisher's exact tests were used for the analysis of the categorical variables. A $P$-value less than $0.05(P<0.05)$ was considered as the statistical significance limit. Compared with previous studies ${ }^{[30]}$, to achieve $\alpha<0.05$ and $\beta=80 \%$ according to QT dispersion, 22 subjects were required in the control group, and 22 subjects were required in the sedation group.

\section{RESULTS}

There was no significant difference between groups in terms of age, gender, BMl and duration of intubation ( $P>0.05$ ) (Table 1). Preoperative STAI-I scores were significantly lower in sedation group compared to the controls $(P<0.05)$ (Table 2$)$. When BAl and STAI scores were compared within the group, no significant difference was observed in Group $S(P=0.102)$. However, the scores were significantly higher in Group $C(P<0.001)$ (Table 2$)$.

In the intergroup evaluation of the cases, MAP values during intraoperative period showed no significant difference $(P>0.05)$ (Figure 1). Heart rate was only significantly reduced in Group $S$ following the $30^{\text {th }}$ second of intubation (Figure 2).

The differences between these groups were examined by multiple comparison tests. According to these results, mean values of QTd measured before induction, at the $1^{\text {st }}$ minute of induction, $30^{\text {th }}$ second of intubation and $4^{\text {th }}$ minute of intubation in sedation group were significantly reduced compared to controls $(P=0.024$; $P=0.027 ; P=0.001 ; P=0.033$, respectively) (Table 3 ).

The mean values of $P$ dispersion measured before induction, at the $3^{\text {rd }}$ minute of induction, $30^{\text {th }}$ second of intubation and $4^{\text {th }}$ minute of intubation in sedation group were significantly reduced compared to the controls ( $P=0.001 ; P=0.020 ; P=0.023$; $P=0.005$, respectively) (Table 4$)$.

\section{DISCUSSION}

The current study showed that the high anxiety levels of patients who underwent coronary bypass surgery had increased QTd and Pd intervals. On the other hand, removal of preoperative anxiety shortened QTd and Pd intervals in pre-induction and following laryngoscopy and TI procedures.

The main reasons of increased level of preoperative anxiety in cardiac surgeries in patients awaiting coronary artery bypass surgery are unawareness of surgery and the fear caused by the lack of knowledge. It is considered normal for intense anxiety in patients a couple of days before the surgery or during the surgery preparations. Lichtor et al. ${ }^{[1]}$ reported that the anxiety level of the patient during the day before surgery was not different from the level of anxiety prior to entering the operating room in the day of surgery. Some of the patients experienced high levels of anxiety and this increased levels has been associated with increased QT dispersion leading to cardiac arrhythmias ${ }^{[11]}$. It has also been shown that mental stress can increase QT dispersion ${ }^{[12]}$. In the present study, we observed that BAI and STAI scores of anxiety-deprived patients, who were waiting for coronary bypass surgery, showed a decrease in preoperative

Table 1. Baseline and intraoperative characteristics of patients.

\begin{tabular}{l|c|c|c}
\multicolumn{1}{c|}{ Characteristic } & Group S (n=30) & Group C (n=31) & P-value \\
\hline Age (years) & $63.4 \pm 8.6$ & $60.5 \pm 11.2$ & 0.272 \\
\hline Body mass index $\left(\mathrm{kg} / \mathrm{m}^{2}\right)$ & $28.3 \pm 3.6$ & $27.1 \pm 3.2$ & 0.159 \\
\hline Male, N (\%) & $25(83.3 \%)$ & $27(87.1 \%)$ & 0.731 \\
\hline Female, N (\%) & $5(16.7 \%)$ & $4(12.9 \%)$ & \\
\hline Duration of intubation (sec) & $9.3 \pm 3.3$ & $8.3 \pm 2.1$ & 0.180 \\
\hline Mean number of grafts & $4.0 \pm 0.9$ & $3.7 \pm 1.3$ & 0.274 \\
\hline
\end{tabular}

Values are expressed as mean (SD) or $\mathrm{n}(\%)$.

Table 2. The difference in BAI and STAI-I values between control and sedation groups.

\begin{tabular}{|c|c|c|c|c|c|c|c|c|}
\hline \multirow[b]{3}{*}{ Preoperative } & \multicolumn{4}{|c|}{ Group S } & \multicolumn{4}{|c|}{ Group C } \\
\hline & \multicolumn{2}{|c|}{ BAI } & \multicolumn{2}{|c|}{ STAI } & \multicolumn{2}{|c|}{ BAI } & \multicolumn{2}{|c|}{ STAI } \\
\hline & $4.8 \pm 4.5$ & (10) 010 & $35.0 \pm 9.6$ & & $5.9 \pm 7.4^{*}$ & & $41.4 \pm 10.4^{*}$ & \\
\hline Before induction & $3.3 \pm 4.7$ & $1-0.102$ & $31.1 \pm 9.5$ & ז ו & $10.2 \pm 8.7^{*}$ & $1<0.001$ & $51.6 \pm 11.1^{*}$ & 180.00 \\
\hline
\end{tabular}

*Indicates statistical significance. STAI and BAI values were significantly higher in the Group C compared to the Group S (P<0.05). 


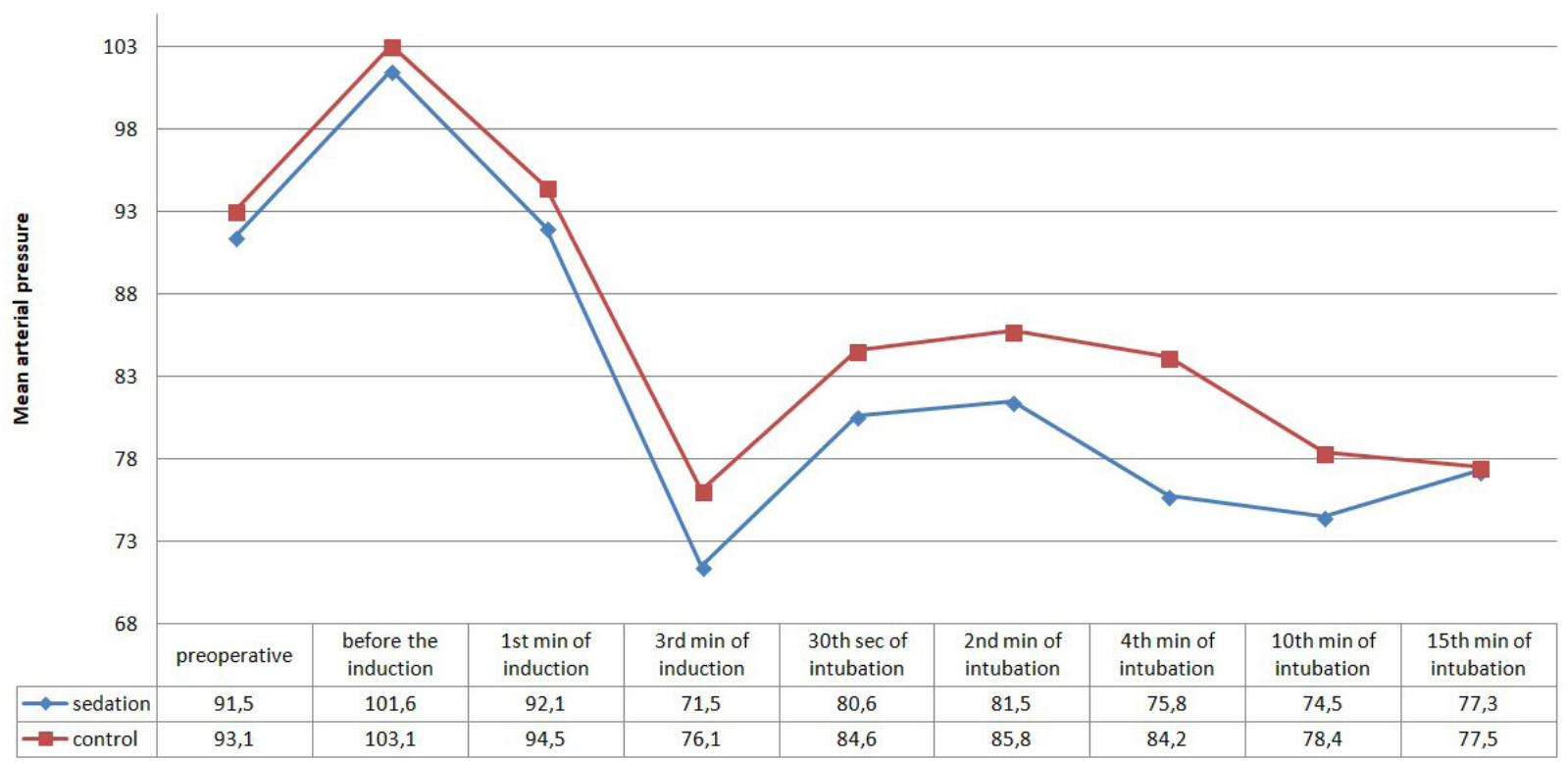

Fig. 1 - Comparison of mean arterial pressure between groups.

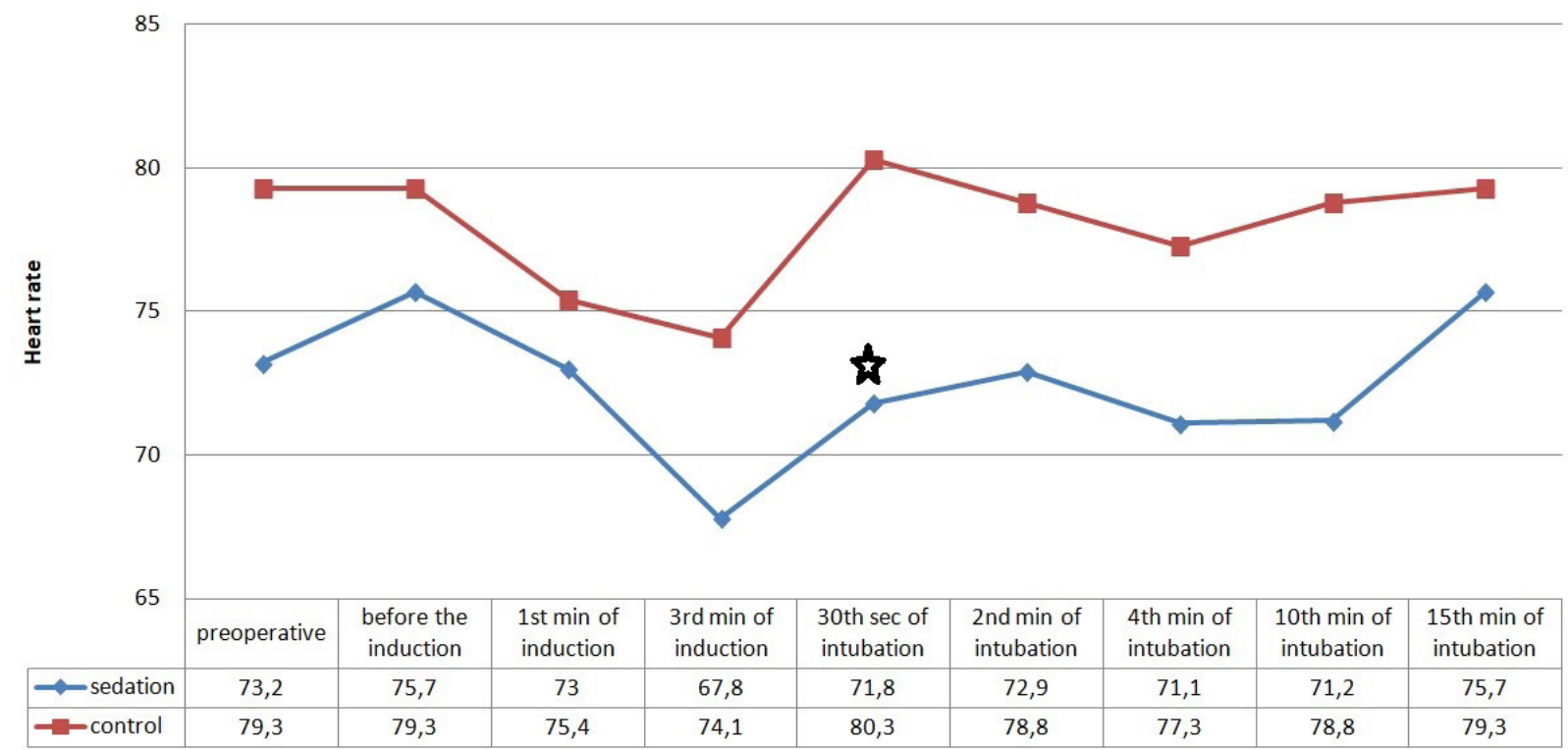

Fig. 2 - Comparison of heart rate between groups.

turnover compared to preoperative turnout, where BAI and STAI scores were increased in the control group. The results of the present study suggest that increased anxiety assessment scores in the control group increased patients' preoperative anxiety. As a result, it significantly increased QTd and Pd intervals before induction. The results of the current study for the effects of anxiety on QTd and Pd were similar to those previously published in the literature ${ }^{[11,12]}$. Due to the prolonged QT dispersion leading to ventricular arrhythmias and the risk of sudden death ${ }^{[32,33]}$, we have shown that it is important to reduce patients' anxiety levels before surgery.

In the literature, the effect of implementation of laryngoscopy, a procedure that prolongs the QTD and Pd interval, and T[ [15-17,30] in QT or P dispersions in a patient undergoing anxiety-relieved coronary bypass surgery has not been reported. Catecholamine release and stress response during laryngoscopy and $\mathrm{TI}$ can 
Table 3. Comparison of QT dispersion between groups in different time periods of intubation.

\begin{tabular}{l|l|l|c}
\hline \multicolumn{1}{c|}{ QT dispersion (msec) } & Group S & Group C & P-value \\
\hline Preoperative & $46.0( \pm 8.7)$ & $46.7( \pm 7.4)$ & 0.734 \\
\hline Before induction & $46.9( \pm 9.6)$ & $51.9( \pm 6.8)$ & $0.024^{*}$ \\
\hline $1^{\text {st }}$ min of induction & $46.4( \pm 7.9)$ & $50.1( \pm 4.3)$ & $0.027^{*}$ \\
\hline $3^{\text {rd }}$ min of induction & $48.0( \pm 6.7)$ & $47.5( \pm 5.4)$ & 0.727 \\
\hline $30^{\text {th }}$ sec of intubation & $50.7( \pm 6.8)$ & $55.9( \pm 4.9)$ & $0.001^{*}$ \\
\hline $2^{\text {nd }}$ min of intubation & $48.6( \pm 6.0)$ & $51.5( \pm 6.0)$ & 0.068 \\
\hline
\end{tabular}

*There was a statistically significant difference between Group $C$ and Group $S(P<0.05)$.

Table 4. Comparison of P dispersion between groups in different time periods of intubation.

\begin{tabular}{l|c|c|c}
\hline P dispersion (msec) & Group S & Group C & P-value \\
\hline Preoperative & $31.2( \pm 3.1)$ & $31.8( \pm 3.4)$ & 0.447 \\
\hline Before induction & $30.4( \pm 3.9)$ & $33.9( \pm 3.9)$ & $0.001^{*}$ \\
\hline $1^{\text {st }}$ min of induction & $31.0( \pm 2.2)$ & $31.9( \pm 3.2)$ & 0.232 \\
\hline $3^{\text {rd }}$ min of induction & $30.4( \pm 2.2)$ & $32.7( \pm 4.8)$ & $0.020^{*}$ \\
\hline $30^{\text {th }}$ sec of intubation & $38.2( \pm 3.1)$ & $40.1( \pm 3.1)$ & $0.023^{*}$ \\
\hline $2^{\text {nd }}$ min of intubation & $34.3( \pm 3.1)$ & $35.9( \pm 2.9)$ & 0.051 \\
\hline $4^{\text {th }}$ min of intubation & $32.2( \pm 2.4)$ & $34.0( \pm 2.3)$ & $0.005^{*}$ \\
\hline
\end{tabular}

*There was a statistically significant difference between Group C and Group $S(P<0.05)$.

lead to severe complications in patients with cardiovascular and cerebral disease, as well as increase the risk of mortality and morbidity ${ }^{[15,34]}$. It has been reported that QT dispersion could be used for HT patients as an indicator for the prevention of sudden cardiac death ${ }^{[35,36]}$. In addition, the QTd interval after TI is prolonged and is even more severe in patients with coronary artery disease and $\mathrm{HT}^{[21]}$. Similar to the QT dispersion, prolonged $\mathrm{Pd}$ interval is considered to be indicative of supraventricular arrhythmias. In many studies, Pd interval has been reported to be a useful and simple method for determining the risk of paroxysmal atrial fibrillation ${ }^{[37]}$. Changes in the P-wave interval in patients with diastolic dysfunction, myocardial ischaemia and acute coronary syndrome have been shown in the literature ${ }^{[38,39]}$ Previous studies have shown that volatile anesthetics and $\mathrm{TI}$ may prolong the QT interval period ${ }^{[24]}$. On the other hand, the use of propofol, as an intravenous anesthetics, may be more appropriate without prolonging the QT interval| ${ }^{[40]}$ and shortens the Pd interval ${ }^{[41]}$. Likewise, administration of fentanyl at a dose of $2 \mathrm{mcg} / \mathrm{kg}$ before induction of propofol has been shown to reduce the length of laryngoscopy and Tl-dependent QTC interval ${ }^{[42]}$. In the current study, we also used drugs with positive effects on laryngoscopy and QT and P dispersion durations during TI. Moreover, we also observed that propofol and fentanyl decreased laryngoscopy and TI-dependent QT and P dispersions.
We found that the elimination of anxiety contributed more positive effects to decrease the QT and Pd times. In the literature, although it has been reported that some benzodiazepines may lead to alterations on electrocardiographic parametres ${ }^{[43,44]}$, there are several studies reporting that lorazepam does not directly affect electrocardiographic parametres. including PR prolongation, QRS widening and QTc interva ${ }^{[45-47]}$. Therefore, we designed this study on the preference of lorazepam as anxiolytic agent.

In conclusion, the results of the present study demonstrate that high anxiety levels in patients with coronary artery disease and coronary bypass surgery have a negative effect through prolonged QT and Pd times. Moreover, anxiety removal before surgery may be useful to prevent ventricular and atrial arrhythmias and associated complications by decreasing the QT and P-wave dispersion durations both during pre-induction and the peak periods of stress response due to laryngoscopy and tracheal intubation.

\section{No financial support.}

No conflict of interest. 


\section{Authors' roles \& responsibilities}

AD Contribution to the design of the study; data collection; statistical analysis; discussion of results; manuscript writing; article review; final approval of the version to be published

YV Contribution to the design of the study; final approval of the version to be published

HY Data collection; statistical analysis; final approval of the version to be published

IK Data collection; final approval of the version to be published

MC Article review; final approval of the version to be published

DC Article review; final approval of the version to be published

IY Analysis, or interpretation of data for the study; final approval of the version to be published

$\mathrm{MB}$

Conception and design of the project; data collection; final approval of the version to be published

$\mathrm{KE}$

Data collection; article review; final approval of the version to be published

\section{REFERENCES}

1. Lindsay GM, Smith LN, Hanlon P, Wheatley DJ. Coronary artery disease patients' perception of their health and expectations of benefit following coronary artery bypass grafting. J Adv Nurs. 2000;32(6):1412-21. doi:10.1046/j.1365-2648.2000.01621.x.

2. Rymaszewska J, Kiejna A, Hadrys T. Depression and anxiety in coronary artery bypass grafting patients. Eur Psychiatry. 2003;18(4):155-60. doi:10.1016/S0924-9338(03)00052-X.

3. Krannich JH, Weyers P, Lueger S, Herzog M, Bohrer T, Elert O. Presence of depression and anxiety before and after coronary artery bypass graft surgery and their relationship to age. BMC Psychiatry. 2007;7:47. doi:10.1186/1471-244X-7-47.

4. Yuksel V, Gorgulu Y, Cinar RK, Huseyin S, Sonmez MB, Canbaz S. Impact of experiencing acute coronary syndrome prior to open heart surgery on psychiatric status. Braz J Cardiovasc Surg. 2016;31 (4):281-6. doi:10.5935/1678-9741.20160064.

5. Garbossa A, Maldaner E, Mortari DM, Biasi J, Leguisamo CP. Effects of physiotherapeutic instructions on anxiety of CABG patients. Rev Bras Cir Cardiovasc. 2009;24(3):359-66. doi:10.1590/S0102-76382009000400016.

6. Fitzsimons D, Parahoo K, Stringer M. Waiting for coronary artery bypass surgery: a qualitative analysis. J Adv Nurs. 2000;32(5):1243-52. doi:10.1046/j.1365-2648.2000.01595.x.

7. Hemingway $\mathrm{H}$, Marmot M. Evidence based cardiology: psychosocial factors in the aetiology and prognosis of coronary heart disease. Systematic review of prospective cohort studies. BMJ [Internet]. 1999 [cited 2019 Apr 27];318(7196):1460-7. Available from: https://www. ncbi.nlm.nih.gov/pubmed/10346775.

8. Argyropoulos SV, Bell CJ, Nutt DJ. Brain function in social anxiety disorder. Psychiatr Clin North Am. 2001;24(4):707-22. doi:10.1016/ S0193-953X(05)70259-8.

9. Sevy S, Papadimitriou GN, Surmont DW, Goldman S, Mendlewicz J. Noradrenergic function in generalized anxiety disorder, major depressive disorder, and healthy subjects. Biol Psychiatry. 1989;25(2):141-52. doi:10.1016/0006-3223(89)90158-3.
10. Schwartz PJ. Idiopathic long QT syndrome: progress and questions. Am Heart J. 1985;109(2):399-411. doi:10.1016/0002-8703(85)90626-X.

11. Kelmanson IA. High anxiety in clinically healthy patients and increased QT dispersion: a meta-analysis. Eur J Prev Cardiol. 2014;21(12):1568-74. doi:10.1177/2047487313501613.

12. Hassan M, Mela A, Li Q, Brumback B, Fillingim RB, Conti JB, et al. The effect of acute psychological stress on QT dispersion in patients with coronary artery disease. Pacing Clin Electrophysiol. 2009;32(9):1 178-83. doi:10.1111/j.1540-8159.2009.02462.x.

13. Shribman AJ, Smith G, Achola KJ. Cardiovascular and catecholamine responses to laryngoscopy with and without tracheal intubation. $\mathrm{Br} J$ Anaesth. 1987;59(3):295-9. doi:10.1093/bja/59.3.295.

14. Russell WJ, Morris RG, Frewin DB, Drew SE. Changes in plasma catecholamine concentrations during endotracheal intubation. $\mathrm{Br}$ J Anaesth. 1981;53(8):837-9. doi:10.1093/bja/53.8.837.

15. Le Heuzey JY, Guize L. Cardiac prognosis in hypertensive patients. Incidence of sudden death and ventricular arrhythmias. Am J Med. 1988;84(1B):65-8. doi:10.1016/S0002-9343(88)91161-8.

16. Ormaetxe JM, Martinez Alday JD, Almendral J, Alfageme Beobide M, Iriarte M. Prognostic significance of ventricular arrhythmias in the presence of pathological left ventricular hypertrophy. Eur Heart J [Internet]. 1993 [cited 2019 Apr 27];14 Suppl J:73-5. Available from: https://www.ncbi.nlm.nih.gov/pubmed/8281968.

17. Zareba W, Moss AJ, le Cessie S. Dispersion of ventricular repolarization and arrhythmic cardiac death in coronary artery disease. Am J Cardiol. 1994;74(6):550-3. doi:10.1016/0002-9149(94)90742-0.

18. Roden DM. Acquired long QT syndromes and the risk of proarrhythmia. J Cardiovasc Electrophysiol. 2000;11(8):938-40. doi:10.1111/j.1540-8167.2000.tb00077.x.

19. Hanci V, Yurtlu S, Karabag T, Okyay D, Hakimoglu S, Kayhan G, et al. Effects of esmolol, lidocaine and fentanyl on P wave dispersion, QT, QTc intervals and hemodynamic responses to endotracheal intubation during propofol induction: a comparative study. Braz J Anesthesiol. 2013;63(3):235-44. doi:10.1016/S0034-7094(13)70223-X.

20. Hanci V, Aydin M, Yurtlu BS, Ayoglu H, Okyay RD, Tas E, et al. Anesthesia induction with sevoflurane and propofol: evaluation of P-wave dispersion, QT and corrected QT intervals. Kaohsiung J Med Sci. 2010;26(9):470-7. doi:10.1016/S1607-551X(10)70074-7.

21. Ay B, Fak AS, Toprak A, Gogus YF, Oktay A. QT dispersion increases during intubation in patients with coronary artery disease. J Electrocardiol. 2003;36(2):99-104. doi:10.1054/jelc.2003.50017.

22. Erdil F, Demirbilek S, Begec Z, Ozturk E, But A, Ozcan Ersoy M. The effect of esmolol on the QTc interval during induction of anaesthesia in patients with coronary artery disease. Anaesthesia. 2009;64(3):24650. doi:10.1111/j.1365-2044.2008.05754.x.

23. Cafiero T, Di Minno RM, Di lorio C. QT interval and QT dispersion during the induction of anesthesia and tracheal intubation: a comparison of remifentanil and fentanyl. Minerva Anestesiol. 2011;77(2):160-5. doi:10.1097/00003643-200606001-00134.

24. Schmeling WT, Warltier DC, McDonald DJ, Madsen KE, Atlee JL, Kampine JP. Prolongation of the QT interval by enflurane, isoflurane, and halothane in humans. Anesth Analg. 1991;72(2):137-44. doi:10.1213/00000539199102000-00001.

25. Kuenszberg E, Loeckinger A, Kleinsasser A, Lindner KH, Puehringer F, Hoermann C. Sevoflurane progressively prolongs the QT interval in unpremedicated female adults. Eur J Anaesthesiol. 2000;17(11):662-4. doi:10.1046/j.1365-2346.2000.00739.x.

26. Barnes LL, Harp D, Jung WS. Reliability generalization of scores on the Spielberger state-trait anxiety inventory. Educational and Psychological Measurement. 2002;62(4):603-18. doi:10.1177/0013164402062004005.

27. Kok L, Sep MS, Veldhuijzen DS, Cornelisse S, Nierich AP, van der Maaten J, et al. Trait anxiety mediates the effect of stress exposure on post- 
traumatic stress disorder and depression risk in cardiac surgery patients. J Affect Disord. 2016;206:216-23. doi:10.1016/j.jad.2016.07.020.

28. Kvaal K, Ulstein I, Nordhus IH, Engedal K. The Spielberger State-Trait Anxiety Inventory (STAI): the state scale in detecting mental disorders in geriatric patients. Int J Geriatr Psychiatry. 2005;20(7):629-34. doi:10.1002/ gps.1330.

29. Beck AT, Epstein N, Brown G, Steer RA. An inventory for measuring clinical anxiety: psychometric properties. J Consult Clin Psychol. 1988;56(6):8937. doi:10.1037/0022-006X.56.6.893.

30. Kiraci G, Demirhan A, Tekelioglu UY, Akkaya A, Bilgi M, Erdem A, et al. A comparison of the effects of lidocaine or magnesium sulfate on hemodynamic response and QT dispersion related with intubation in patients with hypertension. Acta Anaesthesiol Belg [Internet]. 2014 [cited 2019 Apr 27];65(3):81-6. Available from: https://pdfs.semanticscholar. org/2f14/182c9d22c13ddf970d28fb58e3d51952109f.pdf.

31. Lichtor JL, Johanson CE, Mhoon D, Faure EA, Hassan SZ, Roizen MF. Preoperative anxiety: does anxiety level the afternoon before surgery predict anxiety level just before surgery? Anesthesiology [Internet]. 1987 [cited 2019 Apr 27];67(4):595-9. Available from: http://anesthesiology. pubs.asahq.org/article.aspx?articleid=1954221.

32. Glancy JM, Garratt CJ, Woods KL, de Bono DP. QT dispersion and mortality after myocardial infarction. Lancet. 1995;345(8955):945-8. doi:10.1016/ S0140-6736(95)90697-5.

33. Buja G, Miorelli M, Turrini P, Melacini P, Nava A. Comparison of QT dispersion in hypertrophic cardiomyopathy between patients with and without ventricular arrhythmias and sudden death. Am J Cardiol. 1993;72(12):973-6. doi:10.1016/0002-9149(93)91118-2.

34. Kovac AL. Controlling the hemodynamic response to laryngoscopy and endotracheal intubation. J Clin Anesth. 1996;8(1):63-79. doi:10.1016/0952-8180(95)00147-6.

35. Sani IM, Solomon DS, Imhogene OA, Ahmad AM, Bala GS. QT dispersion in adult hypertensives. J Natl Med Assoc [Internet]. 2006 [cited 2019 Apr 27];98(4):631-6. Available from: https://www.ncbi.nlm.nih.gov/ pmc/articles/PMC2569239/.

36. Clarkson PB, Naas AA, McMahon A, MacLeod C, Struthers AD, MacDonald TM. QT dispersion in essential hypertension. QJM. 1995;88(5):327-32. doi:10.1093/oxfordjournals.qjmed.a069073.

37. Chang CM, Lee SH, Lu MJ, Lin CH, Chao HH, Cheng JJ, et al. The role of $P$ wave in prediction of atrial fibrillation after coronary artery surgery.
Int J Cardiol. 1999;68(3):303-8. doi:10.1016/S0167-5273(98)00301-5.

38. Gunduz H, Binak E, Arinc H, Akdemir R, Ozhan H, Tamer A, et al. The relationship between $\mathrm{P}$ wave dispersion and diastolic dysfunction. Tex Heart Inst J [Internet]. 2005 [cited 2019 Apr 27];32(2):163-7. Available from: https://www.ncbi.nlm.nih.gov/pubmed/16107107.

39. Myrianthefs MM, Shandling AH, Startt-Selvester RH, Bernstein SB, Crump R, Lorenz LM, et al. Analysis of the signal-averaged P-wave duration in patients with percutaneous coronary angioplasty-induced myocardial ischemia. Am J Cardiol. 1992;70(7):728-32. doi:10.1016/00029149(92)90549-E.

40. Erdil F, Demirbilek S, Begec Z, Ozturk E, Ersoy MO. Effects of propofol or etomidate on QT interval during electroconvulsive therapy. J ECT. 2009;25(3):174-7. doi:10.1097/YCT.0b013e3181903fa5.

41. Owczuk R, Wujtewicz MA, Sawicka W, Polak-Krzeminska A, SuszynskaMosiewicz A, Raczynska K, et al. Effect of anaesthetic agents on p-wave dispersion on the electrocardiogram: comparison of propofol and desflurane. Clin Exp Pharmacol Physiol. 2008;35(9):1071-6. doi:10.1111/ j.1440-1681.2008.04963.x.

42. Chang DJ, Kweon TD, Nam SB, Lee JS, Shin CS, Park CH, et al. Effects of fentanyl pretreatment on the QTc interval during propofol induction. Anaesthesia. 2008;63(10):1056-60. doi:10.1111/j.1365-2044.2008.05559.x.

43. Kazemzadeh N, Mohammadi S, Emamhadi M, Amirfarhangi A, SanaeiZadeh $\mathrm{H}$. Electrocardiographic Manifestations of Benzodiazepine Toxicity. Iranian Journal of Toxicology Volume [Internet]. 2014 [cited 2019 Apr 27];7(23):952-5. Available from: http://ijt.arakmu.ac.ir/article1-268-en.pdf.

44. Ziegenbein M, Kropp S. Lorazepam-induced prolongation of the QT interval in a patient with schizoaffective disorder and complete AV block. Can J Psychiatry. 2004;49(6):414. doi:10.1177/070674370404900619.

45. Crockford D. Re: Lorazepam-induced prolongation of the QT interval in a patient with schizoaffective disorder and complete AV block. Can J Psychiatry. 2005;50(3):184-5; author reply 5. doi:10.1177/070674370505000315.

46. Harvey AT, Flockhart D, Gorski JC, Greenblatt DJ, Burke M, Werder S, et al. Intramuscular haloperidol or lorazepam and QT intervals in schizophrenia. J Clin Pharmacol. 2004;44(10):1173-84. doi:10.1177/0091270004267807.

47. Reilly JG, Ayis SA, Ferrier IN, Jones SJ, Thomas SH. QTc-interval abnormalities and psychotropic drug therapy in psychiatric patients. Lancet. 2000;355(9209):1048-52. doi:10.1016/S0140-6736(00)02035-3. 